\title{
Risk factors for hypogammaglobulinemia in chronic lymphocytic leukemia patients treated with anti-CD20 monoclonal antibody-based therapies
}

\author{
Caitlin M. McNulty ${ }^{1}$ - Emasenyie A. Isikwei ${ }^{2}$ - Pragya Shrestha ${ }^{2} \cdot$ Melissa R. Snyder $^{3}$ - Brian F. Kabat ${ }^{4} \cdot$ Kari G. Rabe $^{4}$. \\ Susan L. Slager ${ }^{4} \cdot$ Sameer A. Parikh $^{5} \cdot$ Avni Y. Joshi $^{6}$
}

Received: 29 July 2020 / Accepted: 22 September 2020 / Published online: 1 October 2020

(C) Springer-Verlag GmbH Germany, part of Springer Nature 2020

\begin{abstract}
Background Hypogammaglobinemia is a well-recognized complication in chronic lymphocytic leukemia (CLL); however, the risk factors that lead to this complication after treatment with anti-CD20 monoclonal antibodies are not well understood.

Methods Using the Mayo Clinic CLL database, a retrospective chart review was conducted on patients enrolled between January 1995 and September 2017 who had pre- and post-treatment immunoglobulin values. The relationship between immunoglobulin values prior to treatment as well as post-treatment with clinical variables and overall survival (OS) was evaluated. Hypogammaglobinemia was defined as serum immunoglobulin $\mathrm{G}$ (IgG) levels $<500 \mathrm{mg} / \mathrm{dL}$ and evaluated at both baseline and following treatment. Follow-up hypogammaglobinemia was treated as a time-dependent variable in Cox models.

Results A total of 179 patients met the eligibility criteria, 24 (13\%) of whom had hypogammaglobinemia pre-treatment. Patients with hypogammaglobulinemia prior to treatment were more likely to have higher expression of CD49d ( $p$ value $=0.007)$. There was no difference in infection risk, other comorbidities, or OS between the pre- and post-treatment hypogammaglobinemia. In the subset of 155 subjects without hypogammaglobinemia at baseline, 22 developed hypogammaglobinemia. The median time to hypogammaglobinemia for these subjects was 36.6 months.

Conclusion Hypogammaglobinemia is commonly observed in CLL patients, at baseline as well as with the additional use of antiCD20 therapies. The mean time to onset of hypogammaglobinemia after anti-CD20 therapies was 36 months. Time to hypogammaglobinemia does not significantly differ based on any of the CLL clinical factors studied. The presence of hypogammaglobinemia did not appear to impact survival or time to infection.
\end{abstract}

Keywords Hypogammaglobulinemia · Chronic lymphocytic leukemia

Sameer A. Parikh and Avni Y. Joshi are co-senior authors.

Avni Y. Joshi

Joshi.avni@mayo.edu

1 St. Paul Allergy and Asthma, St Paul, MN, USA

2 Department of Molecular Pharmacology and Experimental Therapeutics, Mayo Clinic, Rochester, MN, USA

3 Department of Laboratory Medicine and Pathology, Mayo Clinic, Rochester, MN, USA

4 Division of Biomedical Statistics and Informatics, Mayo Clinic, Rochester, MN, USA

5 Division of Hematology and Oncology, Mayo Clinic, Rochester, MN, USA

6 Division of Allergy and Immunology, Mayo Clinic, 200 First St SW, Rochester, MN 55905, USA

\section{Introduction}

Hypogammaglobulinemia is a common complication of chronic lymphocytic leukemia (CLL). This may affect up to a quarter of patients diagnosed with CLL. [1, 2] Anti-CD20 monoclonal antibodies (rituximab, obinutuzumab, and ofatumumab) are approved for treatment of CLL, either as monotherapy or in combination with conventional chemotherapy (such as fludarabine and cyclophosphamide) and with novel targeted therapies (such as ibrutinib and venetoclax). [3] The risk factors for development of hypogammaglobulinemia and the outcomes of CLL patients treated with anti-CD20 monoclonal antibodies have not been well described.

Hypogammaglobulinemia may occur secondary to changes in the functioning of the nonmalignant $\mathrm{CD}^{-} \mathrm{B}$ cells or decreased immunoglobulin synthesis in the setting of CLL. 
[4] Hypogammaglobulinemia can develop in treatment-naïve patients diagnosed with CLL. [1,5] It is also a well-documented side effect of rituximab when used for malignant and nonmalignant indications [6,7], although patients with prolonged hypogammaglobulinemia have been noted to have a decrease in class-switched memory B cell subsets. [6] Despite this drug's use in a broad range of diseases including cancer and rheumatologic conditions along with many off-label uses in other specialties, there has not been a widespread adoption of immune monitoring during therapy. [8] In part, this is due to the uncertainty surrounding the exact time to development of hypogammaglobulinemia following treatment with anti-CD20 monoclonal antibodies. Some studies suggest that this interval can vary from 6 to 12 months following treatment with rituximab [9] in rheumatologic indications to multiple years in many hematologic and oncologic scenarios . [10, 11] Several studies have indicated the prevalence of hypogammaglobulinemia among heterogeneous patients with previously treated or untreated CLL. [1] However, there remains controversy regarding the value of hypogammaglobulinemia as an indicator of prognosis among patients receiving anti-CD20 therapies. [1, 12] A further complicating factor in assessing the etiology of hypogammaglobulinemia in this patient population includes the increased incidence of malignancy in patients with common variable immunodeficiency (CVID), which can present with hypogammaglobulinemia and recurrent infections and can often go undiagnosed for up to 8 years. [13-15]

To assess the presence of possible risk factors that may predispose patients with CLL to development of hypogammaglobulinemia and whether pre-existing hypogammaglobinemia affected overall survival, a retrospective chart review was conducted using patients enrolled in the Mayo Clinic CLL database who had received treatment with an anti-CD20 monoclonal antibody and who had pre- and post-treatment immunoglobulin G (IgG) values available.

\section{Methods}

The Mayo Clinic CLL database includes patients with a diagnosis of CLL who were evaluated in the Division of Hematology at Mayo Clinic in Rochester, MN, from January 1, 1995, and acquiesced to use of their records for research purposes. [16-18] We identified patients from January 1, 1995, through September 1, 2017, who had received an anti-CD20 monoclonal antibody as a firstline therapy and had IgG values available both pre- (within 1 year of start of therapy) and post-therapy. Patients who also received novel agent therapy in combination with antiCD20 therapies in this study were excluded. Patients who received IVIG therapy during the course of the study were excluded. Demographic data; pre-existing conditions such as autoimmune diseases, diabetes mellitus, inflammatory bowel disease, autoimmune hemolytic anemia, and prior receipt of vaccinations including Prevnar $13 \AA$ and Pneumovax®; smoking status; and history of structural lung disease (such as bronchiectasis) were abstracted from electronic health records. The following infections were also identified by careful chart review for each patient: acute sinusitis, pneumonia, bronchitis, sepsis, influenza, and herpes zoster. Serum IgG values were ascertained clinically via nephelometry (https://www.mayocliniclabs.com/ test-catalog/Overview/8160). The normal serum IgG level in our Clinical Laboratory Improvement Amendments (CLIA)-certified laboratory was $767-1590 \mathrm{mg} / \mathrm{dL}$. We defined hypogammaglobulinemia for our study as serum IgG level of $<500 \mathrm{mg} / \mathrm{dL}$, since this is a clinically relevant value below which patients are known to have increased risk of infections [19-21].

\section{Statistical analysis}

Chi-square and Fisher's exact tests were used to compare discrete variables between patients who did and did not have pretreatment hypogammaglobulinemia. Continuous variables were compared using the $t$ test or Kruskal-Wallis test. Preand post-treatment IgG values were compared using a paired $t$ test. Time to hypogammaglobulinemia was defined as the time from treatment to the time of the post-treatment $\operatorname{IgG}$ test that showed an IgG level $<500 \mathrm{mg} / \mathrm{dL}$. Time to infection was defined as the time from the start of treatment to date of infection. Overall survival (OS) was defined as the time from diagnosis to the date of death. Univariable and multivariable Cox proportional hazard models were used in time-to-event analyses, and Kaplan-Meier plots were used to display time to events. Hypogammaglobulinemia at follow-up was treated as a time-dependent variable in time-to-event analyses. The logrank test was used to compare time-to-event curves. The FineGray method was used to evaluate competing risk of death in the time to infection models.

\section{Results}

\section{Demographics}

One hundred and seventy-nine CLL patients met the criteria for inclusion in the study. Their median age was 61 years (range, 27-83 years), and 73\% were men. Other baseline characteristics are shown in Table 1, including the types of treatment regimens administered. The median time between first $\mathrm{IgG}$ measurement and last assessment was 9.2 years $(95 \% \mathrm{CI}$ : $8.7-9.8$ years). 
Table 1 Characteristics of patient by presence of hypogammaglobulinemia prior to administration of anti-CD20 monoclonal antibody treatment

\begin{tabular}{|c|c|c|c|c|}
\hline & \multicolumn{2}{|l|}{ Pre-treatment IgG } & \multirow[t]{2}{*}{ Total $(N=179)$} & \multirow[t]{2}{*}{$p$ value } \\
\hline & $\geq 500 \mathrm{mg} / \mathrm{dL}(N=155)$ & $<500 \mathrm{mg} / \mathrm{dL}(N=24)$ & & \\
\hline Pre-treatment IgG & & & & $<0.00011$ \\
\hline$N$ & 155 & 24 & 179 & \\
\hline Median & 800.0 & 388.0 & 726.0 & \\
\hline Range & $500.0,2810.0$ & $179.0,498.0$ & $179.0,2810.0$ & \\
\hline Age at CLL diagnosis & & & & 0.751 \\
\hline$N$ & 155 & 24 & 179 & \\
\hline Median & 61.0 & 57.0 & 61.0 & \\
\hline Range & $27.0,83.0$ & $45.0,75.0$ & $27.0,83.0$ & \\
\hline Gender, $n(\%)$ & & & & $0.83^{2}$ \\
\hline Male & $113(72.9 \%)$ & $18(75.0 \%)$ & $131(73.2 \%)$ & \\
\hline Pre-treated beta- 2 microglobulin $(\mu \mathrm{g} / \mathrm{mL})$ & & & & 0.431 \\
\hline$N$ & 138 & 24 & 162 & \\
\hline Median & 2.7 & 3.5 & 2.9 & \\
\hline Range & $1.0,10.9$ & $1.7,7.9$ & $1.0,10.9$ & \\
\hline Baseline B cell count & & & & 0.551 \\
\hline$N$ & 121 & 14 & 135 & \\
\hline Median & 14.4 & 15.0 & 14.4 & \\
\hline Range & $0.5,501.6$ & $2.4,143.3$ & $0.5,501.6$ & \\
\hline Rai stage, $n(\%)$ & & & & $0.18^{2}$ \\
\hline Low risk: stage 0 & $82(52.9 \%)$ & $12(50.0 \%)$ & $94(52.5 \%)$ & \\
\hline Intermediate risk: stages I-II & $57(36.8 \%)$ & $12(50.0 \%)$ & $69(38.5 \%)$ & \\
\hline High risk: stages III-IV & $16(10.3 \%)$ & $0(0.0 \%)$ & $16(8.9 \%)$ & \\
\hline $\mathrm{ZAP} 70, n(\%)$ & & & & $0.18^{2}$ \\
\hline Negative & $56(41.5 \%)$ & $13(56.5 \%)$ & $69(43.7 \%)$ & \\
\hline Positive & $79(58.5 \%)$ & $10(43.5 \%)$ & $89(56.3 \%)$ & \\
\hline Missing & 20 & 1 & 21 & \\
\hline $\mathrm{CD} 38, n(\%)$ & & & & $0.60^{2}$ \\
\hline Negative & $91(59.9 \%)$ & $13(54.2 \%)$ & $104(59.1 \%)$ & \\
\hline Positive & $61(40.1 \%)$ & $11(45.8 \%)$ & $72(40.9 \%)$ & \\
\hline Missing & 3 & 0 & 3 & \\
\hline CD49d, $n(\%)$ & & & & $0.007^{2}$ \\
\hline Negative & $81(62.8 \%)$ & $7(31.8 \%)$ & $88(58.3 \%)$ & \\
\hline Positive & $48(37.2 \%)$ & $15(68.2 \%)$ & $63(41.7 \%)$ & \\
\hline Missing & 26 & 2 & 28 & \\
\hline FISH category, $n(\%)$ & & & & $0.15^{2}$ \\
\hline Normal & $28(19.2 \%)$ & $8(33.3 \%)$ & $36(21.2 \%)$ & \\
\hline Other & $3(2.1 \%)$ & $0(0.0 \%)$ & $3(1.8 \%)$ & \\
\hline $13 q-$ & $39(26.7 \%)$ & $10(41.7 \%)$ & $49(28.8 \%)$ & \\
\hline Trisomy 12 & $34(23.3 \%)$ & $4(16.7 \%)$ & $38(22.4 \%)$ & \\
\hline $11 \mathrm{q}-$ & $29(19.9 \%)$ & $2(8.3 \%)$ & $31(18.2 \%)$ & \\
\hline $17 \mathrm{p}-$ & $13(8.9 \%)$ & $0(0.0 \%)$ & $13(7.6 \%)$ & \\
\hline Missing & 9 & 0 & 9 & \\
\hline$I G H V$ mutation status, $n(\%)$ & & & & $0.87^{2}$ \\
\hline Mutated & $38(28.8 \%)$ & $7(30.4 \%)$ & $45(29.0 \%)$ & \\
\hline Unmutated & $94(71.2 \%)$ & $16(69.6 \%)$ & $110(71.0 \%)$ & \\
\hline Missing & 23 & 1 & 24 & \\
\hline CLL-IPI risk score, $n(\%)$ & & & & $0.31^{2}$ \\
\hline Low risk $(0-1)$ & $15(11.6 \%)$ & $4(17.4 \%)$ & $19(12.5 \%)$ & \\
\hline Intermediate (2-3) & $60(46.5 \%)$ & $9(39.1 \%)$ & $69(45.4 \%)$ & \\
\hline $\operatorname{High}(4-6)$ & $42(32.6 \%)$ & $10(43.5 \%)$ & $52(34.2 \%)$ & \\
\hline Very high (7-10) & $12(9.3 \%)$ & $0(0.0 \%)$ & $12(7.9 \%)$ & \\
\hline Missing & 26 & 1 & 27 & \\
\hline Months from CLL diagnosis to first rituximab treatment & & & & 0.831 \\
\hline$N$ & 155 & 24 & 179 & \\
\hline Median & 20.6 & 26.5 & 22.4 & \\
\hline Range & $0.0,207.3$ & $0.4,134.7$ & $0.0,207.3$ & \\
\hline Treatment type, $n(\%)$ & & & & $0.43^{2}$ \\
\hline Anti-CD20 monoclonal antibody w/ or w/o steroids & $16(10.3 \%)$ & $1(4.2 \%)$ & $17(9.5 \%)$ & \\
\hline Anti-CD20 monoclonal antibody w/ other monoclonal antibodies & $31(20.0 \%)$ & $3(12.5 \%)$ & $34(19.0 \%)$ & \\
\hline Chemoimmunotherapy & $96(61.9 \%)$ & $19(79.2 \%)$ & $115(64.2 \%)$ & \\
\hline Alkylating agent-based therapy & $12(7.7 \%)$ & $1(4.2 \%)$ & $13(7.3 \%)$ & \\
\hline IgG Change from first IgG & & & & 0.11 \\
\hline Median & -94.0 & -12.0 & -87.0 & \\
\hline
\end{tabular}


Table 1 (continued)

\begin{tabular}{|c|c|c|c|c|}
\hline & \multicolumn{2}{|l|}{ Pre-treatment IgG } & \multirow[t]{2}{*}{ Total $(N=179)$} & \multirow[t]{2}{*}{$p$ value } \\
\hline & $\geq 500 \mathrm{mg} / \mathrm{dL}(N=155)$ & $<500 \mathrm{mg} / \mathrm{dL}(N=24)$ & & \\
\hline Range & $-1551.0,2080.0$ & $-269.0,462.0$ & $-1551.0,2080.0$ & \\
\hline IgG change (change $>20 \mathrm{mg} / \mathrm{dL}$ ) from first IgG & & & & $0.09^{2}$ \\
\hline Decrease $>20 \mathrm{mg} / \mathrm{dL}$ & $94(61 \%)$ & $12(50 \%)$ & $106(59 \%)$ & \\
\hline Stable & $21(14 \%)$ & $1(4 \%)$ & $22(12 \%)$ & \\
\hline Increase $>20 \mathrm{mg} / \mathrm{dL}$ & $40(26 \%)$ & $11(46 \%)$ & $51(29 \%)$ & \\
\hline
\end{tabular}

${ }^{1}$ Equal variance two-sample $t$ test. ${ }^{2}$ Chi-square $p$ value

$C D 38$, cluster of differentiation 38, cyclic adenosine diphosphate-ribose hydrolase; $C D 49 d$, cluster of differentiation 49 d, $\alpha 4$ integrin; FISH, fluorescence in situ hybridization; IgG, immunoglobulin G; IGHV, immunoglobulin heavy-chain gene; ZAP70, $\zeta$-associated protein 70

\section{Hypogammaglobulinemia at anti-CD20 monoclonal antibody initiation}

The median serum IgG at baseline was $726 \mathrm{mg} / \mathrm{dL}$ (range, $179-2810 \mathrm{mg} / \mathrm{dL})$. Twenty-four (13\%) patients had hypogammaglobulinemia (serum $\operatorname{IgG}<500 \mathrm{mg} / \mathrm{dL}$ ) at baseline. Table 1 shows the differences in baseline characteristics between patients who did and did not have pretreatment hypogammaglobulinemia. Patients with hypogammaglobulinemia were more likely to have higher expression of CD49d (68\% vs 37\%, $p$ value: 0.007 ) compared with those with no hypogammaglobulinemia. There were no significant differences noted in the remainder of the CLL characteristics at the pre-treatment time point. Additionally, there were no significant differences among patients with and without hypogammaglobulinemia with respect to other comorbidities including diagnosis of diabetes mellitus, autoimmune diseases, inflammatory bowel disease, autoimmune hemolytic anemia, and prior receipt of vaccinations including Prevnar $13 \AA$ and Pneumovax ${ }^{\circledR}$.

\section{Influence of anti-CD20 therapy on development of hypogammaglobulinemia}

The median time interval between pre-treatment and posttreatment IgG level was 10.8 months (range, 0.4137.4 months). After completion of therapy, 106 (59\%) patients had a decrease in their serum IgG level by at least $20 \mathrm{mg} / \mathrm{dL}$ from baseline, 51 (29\%) had an increase in serum $\mathrm{IgG}$ level by at least $20 \mathrm{mg} / \mathrm{dL}$ from baseline, and $22(12 \%)$ did not have a change in serum IgG level greater than $20 \mathrm{mg} /$ dL. Individual changes in serum IgG level are shown in Fig. 1, showing a statistically significant change in IgG levels before and after treatment was observed ( $p$ value $=0.006$ ), with a mean pre-treatment IgG of $851 \mathrm{mg} / \mathrm{dL}$ and a mean posttreatment IgG of $775 \mathrm{mg} / \mathrm{dL}$. Overall, 38 (21\%) patients had serum IgG levels of $<500 \mathrm{mg} / \mathrm{dL}$ after therapy was completed.
Among the 155 patients with no hypogammaglobulinemia prior to CLL therapy, twenty-two patients (14\%) developed hypogammaglobinemia after treatment. The median time to development of hypogammaglobulinemia after therapy was 36.6 months. Baseline characteristics including age, sex, Rai stage, CD49d, FISH group, IGHV mutation status, beta-2 microglobulin level, and ZAP70 did not predict for development of hypogammaglobulinemia. There was a trend for a higher risk of hypogammaglobulinemia among patients with a high expression of CD38 ( $\geq 30 \%)$, although this did not cross the threshold of statistical significance (hazard ratio (HR): 2.2; 95\% CI $0.9-5.4 ; p$ value: 0.08 ). Since there was only a minority of patients who received non-rituximab-based anti-

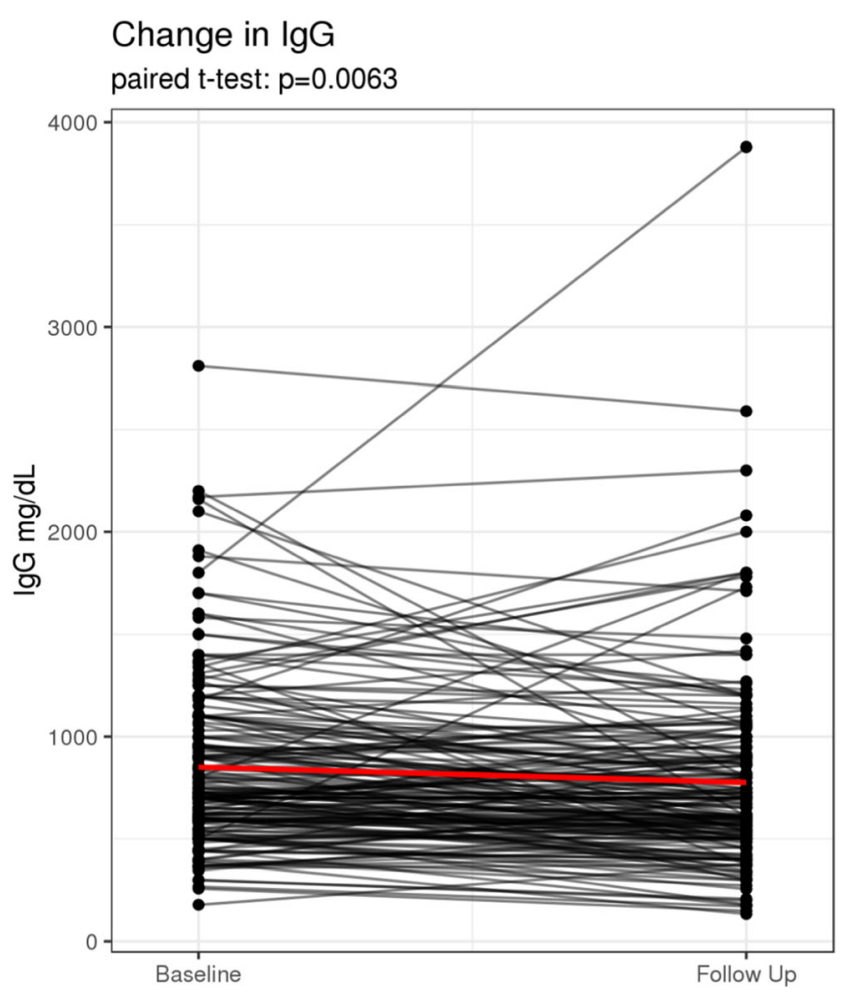

Fig. 1 Change in IgG levels from baseline and post-treatment 
CD20 monoclonal antibody therapy (such as obinutuzumab or ofatumumab), we were unable to determine the impact of different types of anti-CD20 antibody treatments on the risk of subsequent hypogammaglobulinemia.

\section{Risk of infections and the relationship to hypogammaglobulinemia}

In this cohort, 113 patients developed a total of 323 infections after therapy. The different types of infections included sinusitis (91 episodes, $28 \%$ of infections), bronchitis (58 episodes, $18 \%$ ), pneumonia (131 episodes, $41 \%$ ), bloodstream infection (29 episodes, 9\%), and influenza (14 episodes, $4 \%$ ). The median time to any infection was 56.4 months (95\% CI: 47.567.3 months). Of the 113 patients who experienced infections, 41 had a single occurrence of a single infection, 7 had multiple occurrences of a single infection, 10 had multiple infections but a single occurrence of each, and 55 had multiple infections with multiple occurrences of at least one of the infections.

The risk of infection at 1 year was 14\% (10-20\%), 2 years was $24 \%$ (19-32\%), and 3 years was $34 \%$ (27-42\%). Baseline hypogammaglobulinemia did not predict for risk of infectious complications in this cohort of patients (Fig. 2), although the development of hypogammaglobulinemia after treatment was associated with an increased risk of infection (HR: 1.68; $95 \%$
CI 1.04-2.69; $p$ value: 0.03). There was also an increased infection risk by baseline CD49d status.

\section{Overall survival}

The median OS of the entire cohort was 13.5 years. This was not significantly different between patients who had hypogammaglobulinemia at baseline and those who did not (13.4 years vs 13.5 years, respectively, $p$ value: 0.96 ). In univariate models, age $\geq 65$ years (HR 2.9; 95\% CI 1.8-4.8; $p$ value <0.001), unmutated IGHV genes (HR: $2.0 ; 95 \% \mathrm{CI}$ 1.1-3.7; $p$ value: 0.03 ), Rai stage (Rai I/II vs Rai 0 HR: 2.0; 95\% CI 1.2-3.3; $p$ value: 0.01, Rai III/IV vs Rai 0 HR: 2.4; 95\% CI 1.1-5.5; $p$ value: 0.04 ), CLL-IPI (high vs low HR: 3.0; 95\% CI $1.2-8.1 ; p$ value: 0.02 , very high vs low HR: $5.4 ; 95 \%$ CI 1.6-17.9; $p$ value: 0.01 ), and absolute B cell count (B cells $>10 \times 10^{9} /$ L HR: 2.4 ; CI 1.2-4.7; $p$ value: 0.01$)$ were all associated with a shorter OS (Table 2). The development of therapyrelated hypogammaglobulinemia was not significantly associated with $\mathrm{OS}(\mathrm{HR}=0.7 ; 95 \%$ CI $0.4-1.2 ; p$ value $=0.19)$.

Though there were a number of significant factors in the univariate analysis, many of the factors are a part of the CLLIPI (i.e., age, Rai stage, and $I G H V$ mutation status). Hence, we only included CLL-IPI and absolute B cell in the multivariable model; CLL-IPI was not statistically significant, and absolute B cell count $\left(\mathrm{B}\right.$ cells $\left.>10 \times 10^{9} / \mathrm{L}\right)$ approached the threshold of
Fig. 2 Time to infection by pretreatment hypogammaglobulinemia

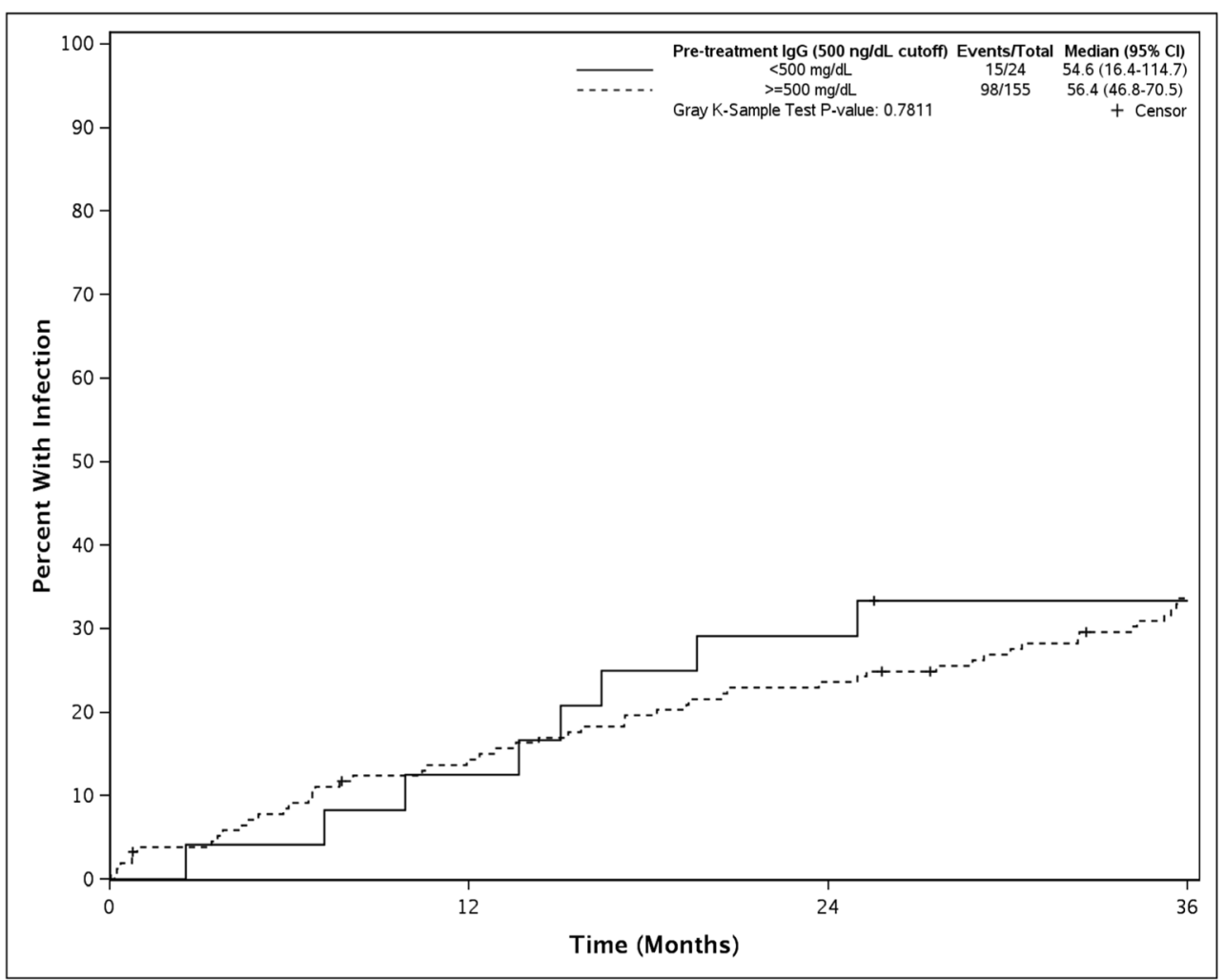


Table 2 Univariate and multivariable analyses of overall survival

\begin{tabular}{|c|c|c|c|c|c|}
\hline & \multirow[t]{2}{*}{$N$} & \multicolumn{2}{|l|}{ Univariate } & \multicolumn{2}{|l|}{ Multivariable } \\
\hline & & $\operatorname{HR}(95 \% \mathrm{CI})$ & $p$ value & $\operatorname{HR}(95 \% \mathrm{CI})$ & $p$ value \\
\hline \multicolumn{3}{|l|}{ Age } & $<0.001$ & - & - \\
\hline Age $<65$ & 114 & ref & & & \\
\hline Age $\geq 65$ & 65 & $2.9(1.8-4.7)$ & & & \\
\hline \multicolumn{3}{|l|}{ Gender } & 0.36 & - & - \\
\hline Female & 48 & ref & & & \\
\hline Male & 131 & $1.3(0.7-2.1)$ & & & \\
\hline \multicolumn{4}{|l|}{ Rai stage } & - & - \\
\hline Low risk: stage 0 & 94 & ref & & & \\
\hline Intermediate risk: stages I-II & 69 & $2.0(1.2-3.2)$ & 0.01 & & \\
\hline High risk: stages III-IV & 16 & $2.4(1.1-5.5)$ & 0.04 & & \\
\hline \multicolumn{3}{|l|}{$I G H V$ mutation status } & 0.03 & - & - \\
\hline Mutated & 45 & ref & & & \\
\hline Unmutated & 110 & $2.0(1.1-3.7)$ & & & \\
\hline \multicolumn{6}{|l|}{ CLL-IPI risk category } \\
\hline Low risk $(0-1)$ & 19 & ref & & ref & \\
\hline Intermediate risk $(2-3)$ & 69 & $1.8(0.7-4.7)$ & 0.23 & $0.9(0.3-2.8)$ & 0.90 \\
\hline High risk (4-6) & 52 & $3.0(1.2-8.1)$ & 0.02 & $1.5(0.5-4.6)$ & 0.52 \\
\hline Very high risk (7-10) & 12 & $5.4(1.6-17.9)$ & 0.006 & $1.5(0.3-8.4)$ & 0.64 \\
\hline \multicolumn{3}{|l|}{ B cell class } & 0.01 & & 0.06 \\
\hline B cells $\leq 10 \times 10^{9} / \mathrm{L}$ & 51 & ref & & ref & \\
\hline B cells $>10 \times 10^{9} / \mathrm{L}$ & 84 & $2.4(1.2-4.7)$ & & $2.3(1.0-5.4)$ & \\
\hline \multicolumn{3}{|c|}{ Baseline hypogammaglobulinemia } & 0.96 & - & - \\
\hline $\mathrm{IgG}<500 \mathrm{mg} / \mathrm{dL}$ & 24 & $1.0(0.5-2.0)$ & & & \\
\hline $\mathrm{IgG} \geq 500 \mathrm{mg} / \mathrm{dL}$ & 155 & ref & & & \\
\hline \multicolumn{3}{|c|}{ Follow-up hypogammaglobulinemia } & 0.19 & - & - \\
\hline $\mathrm{IgG}<500 \mathrm{mg} / \mathrm{dL}$ & 38 & $0.7(0.4-1.2)$ & & & \\
\hline $\mathrm{IgG} \geq 500 \mathrm{mg} / \mathrm{dL}$ & 141 & ref & & & \\
\hline \multicolumn{3}{|l|}{ Post TX infection } & 0.39 & - & - \\
\hline No infection & 66 & ref & & & \\
\hline Any infection & 113 & $1.2(0.8-2.1)$ & & & \\
\hline
\end{tabular}

ref, reference; $H R$, hazard ratio; $C I$, confidence interval

The CLL-IPI consists of 5 variables including age, serum beta- 2 microglobulin, TP53 disruption (CLL FISH 17p or TP53), IGHV mutation status, and Rai stage. Since age, IGHV mutation status, and Rai stage are already included in the CLL-IPI, these variables were not assessed in the multivariable model separately, although they were significant in univariate analyses statistical significance $(\mathrm{HR}=2.3 ; 95 \%$ CI $1.0-5.4 ; p$ value $=$ 0.06) (Fig. 3).

\section{Discussion}

In our retrospective study of CLL patients with initial treatment of anti-CD20 therapy, we evaluated for the presence of hypogammaglobulinemia, both prior to and after initial treatment. A higher expression of CD49d was found among the 24 patients with pre-treatment hypogammaglobulinemia as compared with patients with a normal pre-treatment immunoglobulin level. After completion of anti-CD20 therapy, 21\% patients had a decrease in their serum IgG level which was less than $500 \mathrm{mg} / \mathrm{dL}$ (hypogammaglobulinemia). Among the 155 patients with normal IgG level prior to treatment, 22 developed post-treatment hypogammaglobinemia with the median time of development of hypogammaglobulinemia after therapy of 36.6 months. We were not able to find any associations between the baseline characteristics and development of hypogammaglobulinemia. The OS of the patients was not significantly different between patients with and without 
Fig. 3 a Overall survival of all patients $(n=179)$. b Overall survival by baseline hypogammaglobulinemia. Overall survival is compared between patients who had hypogammaglobulinemia (solid) and those who had normal immunoglobulin $\mathrm{G}$ (dashed) at initiation of anti-CD20 monoclonal antibody treatment a

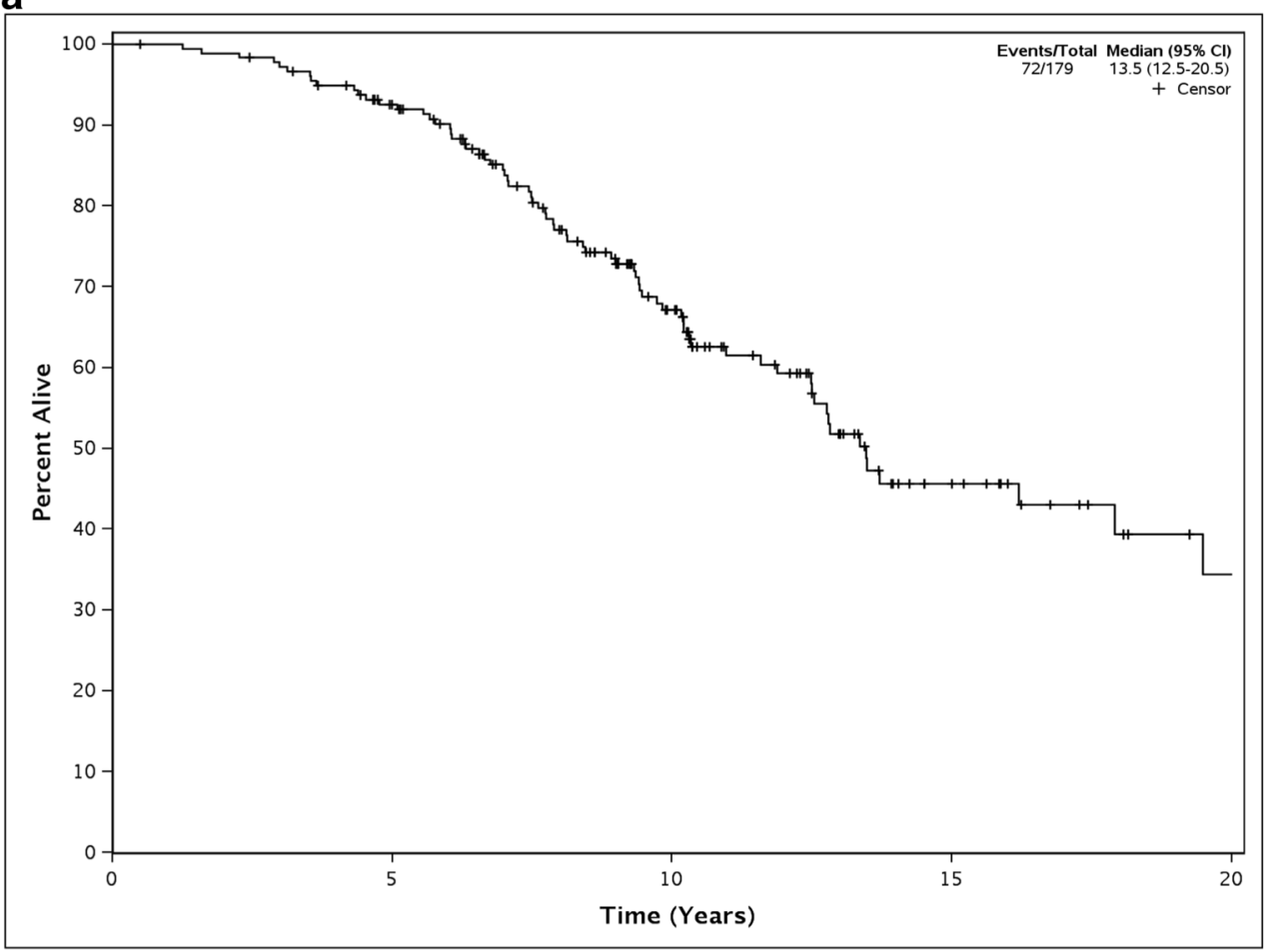

b

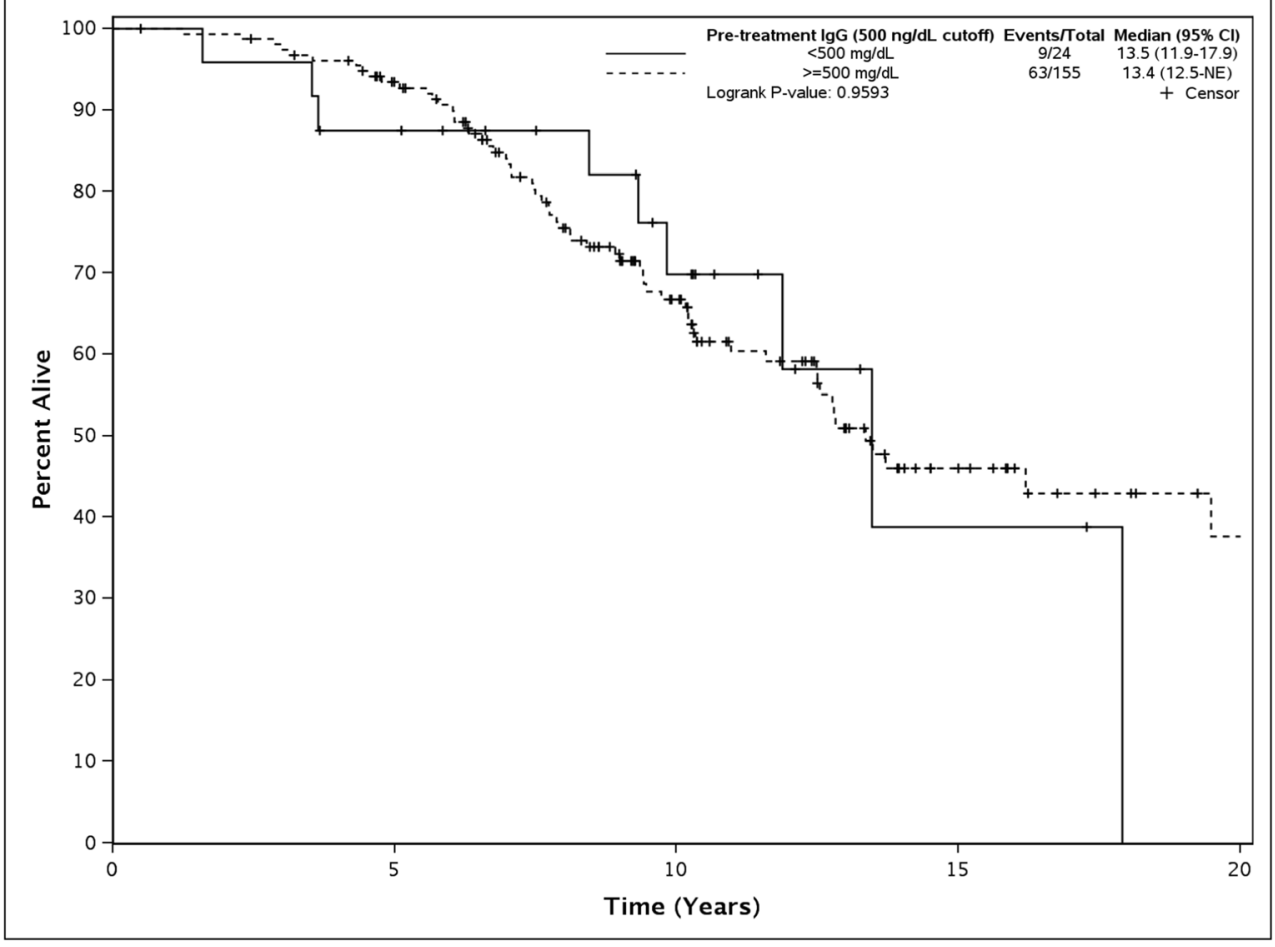

pre-treatment hypogammaglobulinemia. A recent publication by Barmettler et al. looked at overall rituximab use in their health system, $78 \%$ of which were cancer patients and reported worsening hypogammaglobulinemia following rituximab administration with overall increase in severe infections (from
17.2 to $21.7 \%$ ) and also showed increased mortality associated with increasing age, male sex, and severe infectious complications. [8] Our study did not show any association with overall infections and OS; OS of patients with high Rai risk and CLL-IPI risk category was lower in our cohort. In 
addition, our definition of hypogammaglobulinemia was stricter with a cutoff of $500 \mathrm{mg} / \mathrm{dL}$, while Barmettler et al. used IgG levels less than $600 \mathrm{mg} / \mathrm{dL}$ as their cutoff for defining hypogammaglobulinemia. This result was similar to the one recent publication by Anderson et al., where they did not find any associations between low IgG levels and infections, but noted older age group, high Binet stage, high beta- $2 \mathrm{mi}-$ croglobulin, and IgG deficiency to be associated with shorter OS. [12] Pre-treatment inflammatory bowel disease (IBD) was noted in $3(1.9 \%)$ of those with normal $\operatorname{IgG}$ at diagnosis. The presence of pre-existing gastrointestinal disorders was assessed, as this has been shown to be increased in the CVID population, and was not found to be associated with the development of hypogammaglobulinemia. [14]

In our study, there were no significant differences in $\operatorname{IgG}$ levels based on age, sex, beta- 2 microglobulin, B cell count, ZAP70, expression of CD38, or IGHV mutation, as reported previously by our group. [1] However, higher expression of CD49d [1] was noted among patients with pre-treatment hypogammaglobulinemia. High expression of CD49d independently has shown to predict poor survival in patients with CLL. [22] The precise mechanism by which CD49d expression influences serum IgG level still remains unclear at this time.

The mechanism of action for anti-CD20 therapies is believed to be cell death through direct, complement-dependent, and antibody-dependent cellular cytotoxicity. [8, 23, 24] B cell depletion and subsequent normalization require at least 6-9 months or even longer. [25] This, however, can differ depending on underlying disease pathophysiology (malignancy, autoimmune conditions). In a recent retrospective study done by Theil et al. [26], ANCA-associated vasculitis treated with rituximab therapy was found to have long-lasting depletion of B cells causing hypogammaglobulinemia, which maybe unique to the underlying autoimmune pathophysiology of this disease. In our study, in patients with normal IgG level prior to treatment, the median time of development of hypogammaglobulinemia after therapy was 36.6 months. This group did show higher risk of infections; hence, awareness of this timeline for the development of post-treatment hypogammaglobinemia may prompt clinicians to investigate the development of hypogammaglobinemia in high-risk patient population, especially with high Rai risk category and high CLL-IPI risk category.

There are several limitations to our study, including that this is a retrospective analysis which is subject to sampling and misclassification bias. In that, differences may exist in patients who presented to the hospital and had immunoglobulin levels checked, in realm of severity of clinical presentation and whether this could have prompted clinical evaluation. Our report is also a single-institution study, and the findings may not be generalizable. Because of referral nature of practice at our tertiary care institution, we did not have complete, reliable information about all forms of infectious and noninfectious complications related to hypogammaglobulinemia in patients. In terms of studying the exact effect of the type of anti-CD20 agent used, there was only a minority of patients who received non-rituximab-based anti-CD20 monoclonal antibody therapy (such as obinutuzumab or ofatumumab); hence, we were unable to determine the impact of different types of anti-CD20 antibody treatments on the risk of subsequent hypogammaglobulinemia. In addition to these, we had strict inclusion criteria where we looked for IgG values immediately prior and after the initial treatment but excluded subsequent treatment visits and also patients on IVIG therapy. This was done to avoid confounding bias from further treatment received by the patients; however, this might have limited the generalizability of these findings to a broader population. Finally, patients with low immunoglobulin levels and recurrent infections after anti-CD20 therapy may have baseline subclinical immune dysfunction, including CVID, which may have been unmasked by anti-CD20 therapies. Finally, we did not include patients who received novel agent therapy in combination with anti-CD20 therapies in this study.

In summary, our study shows that CLL patients with higher expression of CD49d are more likely to have hypogammaglobulinemia at diagnosis. Comorbidities at baseline such as history of autoimmune disorders, inflammatory bowel disease, and diabetes mellitus were not associated with a higher risk of hypogammaglobulinemia. Among those with normal immunoglobulin levels at treatment initiation, the median time to development of hypogammaglobulinemia following anti-CD20 antibody-based therapy was about 36 months, and no baseline factors predicted the development of hypogammaglobulinemia following treatment. The presence of hypogammaglobulinemia at baseline and its subsequent occurrence after therapy did not seem to impact OS, but post-treatment hypogammaglobinemia did affect the infection risk.

Our study improves our understanding of timing posttreatment hypogammaglobinemia and its associated increased infection risk.

Acknowledgments Dr. Isikewei is funded under NIH trainee grant: T32 GM008685-21.

Funding Internal, Departmental Funds at Mayo Clinic.

\section{Compliance with ethical standards}

Conflict of interest Research funding has been provided to the institution from Pharmacyclics, MorphoSys, Janssen, AstraZeneca, TG Therapeutics, Celgene, AbbVie, and Ascentage Pharma for clinical studies in which Sameer A. Parikh is a principal investigator. Sameer A. Parikh has also participated in Advisory Board meetings of Pharmacyclics, AstraZeneca, Genentech, Gilead, GlaxoSmithKline, Verastem Oncology, and AbbVie (he was not personally compensated for his participation). 


\section{References}

1. Parikh SA, Leis JF, Chaffee KG, Call TG, Hanson CA, Ding W, Chanan-Khan AA, Bowen D, Conte M, Schwager S, Slager SL, van Dyke DL, Jelinek DF, Kay NE, Shanafelt TD (2015) Hypogammaglobulinemia in newly diagnosed chronic lymphocytic leukemia: natural history, clinical correlates, and outcomes. Cancer 121(17):2883-2891

2. Freeman JA, Crassini KR, Best OG, Forsyth CJ, Mackinlay NJ, Han P, Stevenson W, Mulligan SP (2013) Immunoglobulin G subclass deficiency and infection risk in 150 patients with chronic lymphocytic leukemia. Leuk Lymphoma 54(1):99-104

3. Hallek M (2017) Chronic lymphocytic leukemia: 2017 update on diagnosis, risk stratification, and treatment. Am J Hematol 92(9): 946-965

4. Wadhwa PD, Morrison VA (2006) Infectious complications of chronic lymphocytic leukemia. Semin Oncol 33(2):240-249

5. Tsai H-T et al (2009) Evidence of serum immunoglobulin abnormalities up to 9.8 years before diagnosis of chronic lymphocytic leukemia: a prospective study. Blood 114(24):4928

6. Kaplan B, Kopyltsova Y, Khokhar A, Lam F, Bonagura V (2014) Rituximab and immune deficiency: case series and review of the literature. J Allergy Clin Immunol Pract 2(5):594-600

7. Makatsori M, Kiani-Alikhan S, Manson AL, Verma N, Leandro M, Gurugama NP, Longhurst HJ, Grigoriadou S, Buckland M, Kanfer E, Hanson S, Ibrahim MAA, Grimbacher B, Chee R, Seneviratne SL (2014) Hypogammaglobulinaemia after rituximab treatmentincidence and outcomes. Qjm 107(10):821-828

8. Barmettler S, Ong MS, Farmer JR, Choi H, Walter J (2018) Association of immunoglobulin levels, infectious risk, and mortality with rituximab and hypogammaglobulinemia. JAMA Netw Open 1(7):e184169

9. Mitchell C, Crayne CB, Cron RQ (2019) Patterns of B cell repletion following rituximab therapy in a pediatric rheumatology cohort. ACR Open Rheumatol 1(8):527-532

10. FDA. Rituximab (Rituxan) product information. 1997; Available from: https://www.accessdata.fda.gov/drugsatfda_docs/label/2012/ 103705s5367s53881bl.pdf

11. Administratio, U.F.a.D. Highlights of prescribing information ofatumumab. 2009; Available from: http://www.accessdata.fda. gov/drugsatfda_docs/label/2009/125326lbl.pdf

12. Andersen MA, Vojdeman FJ, Andersen MK, Brown PN, Geisler $\mathrm{CH}$, Weis Bjerrum O, Niemann CU (2 016 ) Hypogammaglobulinemia in newly diagnosed chronic lymphocytic leukemia is a predictor of early death. Leuk Lymphoma 57(7): 1592-1599

13. Salavoura K, Kolialexi A, Tsangaris G, Mavrou A (2008) Development of cancer in patients with primary immunodeficiencies. Anticancer Res 28(2b):1263-1269

14. Quinti I, Soresina A, Spadaro G, Martino S, Donnanno S, Agostini C, Claudio P, Franco D, Maria Pesce A, Borghese F, Guerra A, Rondelli R, Plebani A, Italian Primary Immunodeficiency Network (2007) Long-term follow-up and outcome of a large cohort of patients with common variable immunodeficiency. J Clin Immunol 27(3):308-316
15. Cunningham-Rundles C, Siegal FP, Cunningham-Rundles S, Lieberman P (1987) Incidence of cancer in 98 patients with common varied immunodeficiency. J Clin Immunol 7(4):294-299

16. Wang Y et al. (2019) Clinical characteristics and outcomes of Richter transformation: experience of 204 patients from a single center. Haematologica

17. Fang H, Reichard KK, Rabe KG, Hanson CA, Call TG, Ding W, Kenderian SS, Muchtar E, Schwager SM, Leis JF, Chanan-Khan AA, Slager SL, Braggio E, Smoley SA, Kay NE, Shanafelt TD, van Dyke DL, Parikh SA (2019) IGH translocations in chronic lymphocytic leukemia: clinicopathologic features and clinical outcomes. Am J Hematol 94(3):338-345

18. Hampel PJ, Larson MC, Kabat B, Call TG, Ding W, Kenderian SS, Bowen D, Boysen J, Schwager SM, Leis JF, Chanan-Khan AA, Muchtar E, Hanson CA, Slager SL, Kay NE, Chaffee KG, Shanafelt TD, Parikh SA (2018) Autoimmune cytopenias in patients with chronic lymphocytic leukaemia treated with ibrutinib in routine clinical practice at an academic medical Centre. Br J Haematol 183(3):421-427

19. Chin T, O’Neill Shigeoka A (2004) Bruton agammaglobulinemia. eMedicine Journal [serial online]

20. Eijkhout HW, van der Meer JWM, Kallenberg CGM, Weening RS, van Dissel JT, Sanders LAM, Strengers PFW, Nienhuis H, Schellekens PTA, for the Inter-University Working Party for the Study of Immune Deficiencies (2001) The effect of two different dosages of intravenous immunoglobulin on the incidence of recurrent infections in patients with primary hypogammaglobulinemia: a randomized, double-blind, multicenter crossover trial. Ann Intern Med 135(3):165-174

21. Quartier P, Debré M, de Blic J, de Sauverzac R, Sayegh N, Jabado N, Haddad E, Blanche S, Casanova JL, Edvard Smith CI, le Deist F, de Saint Basile G, Fischer A (1999) Early and prolonged intravenous immunoglobulin replacement therapy in childhood agammaglobulinemia: a retrospective survey of 31 patients. J Pediatr 134(5):589-596

22. Bulian P, Shanafelt TD, Fegan C, Zucchetto A, Cro L, Nückel H, Baldini L, Kurtova AV, Ferrajoli A, Burger JA, Gaidano G, del Poeta G, Pepper C, Rossi D, Gattei V (2014) CD49d is the strongest flow cytometry-based predictor of overall survival in chronic lymphocytic leukemia. J Clin Oncol 32(9):897-904

23. Glennie MJ, French RR, Cragg MS, Taylor RP (2007) Mechanisms of killing by anti-CD20 monoclonal antibodies. Mol Immunol 44(16):3823-3837

24. Taylor RP, Lindorfer MA (2008) Immunotherapeutic mechanisms of anti-CD20 monoclonal antibodies. Curr Opin Immunol 20(4): 444-449

25. Kimby E (2005) Tolerability and safety of rituximab (MabThera). Cancer Treat Rev 31(6):456-473

26. Thiel J, Rizzi M, Engesser M, Dufner AK, Troilo A, Lorenzetti R, Voll RE, Venhoff N (2017) B cell repopulation kinetics after rituximab treatment in ANCA-associated vasculitides compared to rheumatoid arthritis, and connective tissue diseases: a longitudinal observational study on 120 patients. Arthritis Res Ther 19(1):101

Publisher's note Springer Nature remains neutral with regard to jurisdictional claims in published maps and institutional affiliations. 